\title{
Perfil dos indivíduos que cursam educação profissional no Brasil *
}

\author{
Isabel Musse ** \\ Ana Flavia Machado ${ }^{* * *}$
}

\begin{abstract}
Resumo
A educação profissional é um tema de extrema relevância na atualidade brasileira e, cada vez mais, surgem instituições públicas e particulares visando qualificar o indivíduo para o mercado de trabalho. No entanto, pouco se sabe sobre quem são os indivíduos que cursaram qualificação hoje no Brasil e se há um diferencial de rendimento favorável aos mesmos. Para que se conheçam os perfis, é usado o Suplemento da Pesquisa Nacional por Amostra de Domicílio (PNAD) de 2007. Através de análises descritivas e de estimação de modelos econométricos, concluiu-se que os inativos são os que mais procuram este tipo de qualificação. Com relação aos ocupados, observa-se que cursar Educação Profissional acresce o rendimento no mercado de trabalho.
\end{abstract}

Palavras-chave: Qualificação profissional; Mercado de trabalho; Rendimento.

\begin{abstract}
Profiles of the individuals seeking professional qualification in Brazil

Professional qualification is a topic of utmost importance in Brazil and there are an increasing number of public and private institutions in order to qualify the individual for the job market. However, we do not know a lot about the individuals who take part in this type of training in Brazil or if there is a wage gap which favors those who do. The National Household Sample (PNAD) from 2007 is used to gain information on the profiles. Through descriptive analysis and estimation of econometric models, it was concluded that this type of qualification is mostly sought after by the unemployed. Regarding those in work, it is observed that professional qualification leads to an increase in income in the labor market.
\end{abstract}

Keywords: Professional qualification; Labor market; Wage.

JEL J01; J08; J24.

\section{Introdução}

A qualificação profissional, ou formação inicial e continuada, é direcionada para o mercado de trabalho e não eleva o nível de escolaridade do indivíduo. Além disso, o curso pode ser oferecido por diversas instituições (de igrejas a sindicatos) com duração e conteúdo variáveis. Já o curso técnico de nível médio fornece ao indivíduo o diploma de técnico junta ou posteriormente à

* Trabalho recebido em 13 de agosto de 2010 e aprovado em 12 de março de 2012.

** Consultora da Fundação Itaú Social, São Paulo, SP, Brasil. E-mail: musse.isabel@gmail.com.

*** Professora Associada do Centro de Desenvolvimento e Planejamento Regional de Minas Gerais / Universidade Federal de Minas Gerais (Cedeplar/UFMG), Belo Horizonte, MG, Brasil. E-mail: afmachad@cedeplar.ufmg.br. 
conclusão do ensino médio, além de possuir legislação própria e só poder ser oferecido por instituições credenciadas junto ao poder público. Tais regras também se aplicam a cursos de graduação tecnológica, os quais, no entanto, possuem como pré-requisito a conclusão do ensino médio, e, quando concluídos, o indivíduo recebe o diploma de ensino superior. Esta última modalidade possui, como nos demais casos, demandas do mercado de trabalho como motivação principal e, muitas vezes, estão estruturados em temas ligados a setores tecnológicos da economia. Esta divisão foi oficializada pela Lei de Diretrizes e Bases da Educação Nacional (LDB), de 20 de dezembro de 1996, que divide a educação profissional nos três níveis aqui apresentados, de acordo com o nível de escolaridade exigido (básico, técnico e tecnológico). Segundo esta lei, a educação profissional

(...) integrada às diferentes formas de educação, ao trabalho, à ciência e à tecnologia, conduz ao permanente desenvolvimento de aptidões para a vida produtiva. $\mathrm{O}$ aluno matriculado ou egresso do ensino fundamental, médio e superior, bem como o trabalhador em geral, jovem ou adulto, contará com a possibilidade de acesso à educação profissional (Faria, 2008, p.1)

O objetivo deste trabalho é descrever o perfil do brasileiro que cursa ou já cursou a educação profissional, tema de extrema relevância nos dias atuais, pois sabe-se que a qualificação dos trabalhadores é um importante determinante de sua produtividade e, consequentemente, crucial para mensurar a produtividade de empresas e, no agregado, do país. Além disso, a educação profissional é, também, uma forma de se facilitar a inserção no mercado de trabalho. No caso brasileiro, em que a qualificação é assunto não somente de instituições privadas, mas, principalmente, de instituições públicas, conhecer o indivíduo que se qualifica é fundamental para tornar as políticas públicas mais efetivas, identificar suas fraquezas e direcioná-las para o público alvo das mesmas com maior eficácia.

Para atingir seu objetivo, este artigo se concentra, na primeira seção, em uma revisão bibliográfica das principais abordagens econômicas sobre educação profissional, além de traçar uma trajetória das principais mudanças na qualificação exigida dos trabalhadores no Brasil e no mundo de acordo com o modo de produção majoritário da época. Na próxima seção, é apresentada a base de dados PNAD 2007 e os modelos econométricos estimados. Na terceira, é feita uma análise dos resultados, abordando tanto a análise descritiva quanto a análise dos resultados dos modelos. Finalmente, é apresentado o perfil do brasileiro que cursa educação profissional segundo as conclusões deste trabalho.

\section{A trajetória da educação profissional no Brasil}

Nas últimas décadas, a economia mundial vem passando por várias transformações que têm afetado o modo de produção e as relações trabalhistas. Desde mudanças tecnológicas (como a invenção da máquina a vapor e, mais 
recentemente, a informatização), até alterações nas relações comerciais entre os países que, hoje, são marcadas pela liberalização. Todos estes fatores afetam, inevitavelmente, a qualificação exigida dos trabalhadores, objeto de estudo deste trabalho.

Na década de 1990, a busca pela qualidade e competitividade nas indústrias brasileiras se acirrou, com uma nova tendência de focalização da produção em um setor específico e terceirização dos demais. No entanto, paralelamente a este processo de enriquecimento da produção, houve uma precarização das condições de trabalho como resultado da terceirização (Ruas, 1993 apud Leite, 1994). Ainda assim, nota-se uma maior preocupação das empresas com a estabilidade e qualificação da mão-de-obra, refletida nos centros de qualificação profissional que surgem neste período (Leite, 1993, p. 575).

Segundo Kuenzer (1999), a política de capacitação profissional no Brasil na época do processo de industrialização reflete o modo de produção taylorista/fordista, em que o trabalhador é treinado para executar certa tarefa específica, ausentando qualquer preocupação com a geração de conhecimento sobre aquela função. Em Pires (2001), é feita uma reflexão acerca do papel do ensino profissionalizante ao longo da década de 1970 no Brasil, período no qual houve um destaque para o ensino técnico como impulsor do crescimento econômico, criticando a visão simplista de subordinar a escola às demandas do mercado de trabalho. Apesar desta ter sido a visão que prevaleceu na formulação de políticas públicas durante os anos 70, o autor destaca que este pensamento tem sofrido transformações nas últimas décadas, em face a processos produtivos cada vez mais automatizados, que exigem do trabalhador maior capacidade de adaptação e senso crítico. Por esta razão, retoma-se a valorização da educação formal e do ensino profissionalizante mais abrangente, como pode ser percebido nas políticas desenvolvidas a partir da década de 1990.

O governo brasileiro, através do SINE (Sistema Nacional de Emprego), sob a coordenação e direção do Ministério do Trabalho e Emprego (MTE), vem modificando sua forma de atuação na qualificação do trabalhador para o mercado de trabalho ${ }^{1}$. Até meados da década de 1990, a educação foi tratada de forma segmentada, isto é, investimentos e políticas eram articulados de forma separada para os diversos níveis da educação. Assim, foi dada grande atenção à educação fundamental em detrimento do ensino médio e superior, o qual teve seu orçamento reduzido pela metade ao longo daquela década. Tal medida revelou-se falha, pois todo o processo educacional é um ciclo que não pode ser interrompido por descaso

(1) Além desta forma de atuação, que corresponde a uma ação direta sobre o mercado de trabalho, intermediando a mão-de-obra e financiando treinamento dos trabalhadores, o Estado também age de forma indireta, com políticas passivas que prestam auxílio ao trabalhador desempregado e se esforçam para reduzir a oferta de mão-de-obra (como, por exemplo, seguro desemprego e redução da jornada de trabalho). 
ou falta de recursos. A mesma conduta foi observada em relação à educação profissional, que sofreu sérios cortes de orçamento e uma diminuição da atenção do governo federal, ficando a mercê de parcerias dos governos estaduais e municipais com instituições privadas ou organizações não-governamentais (Haddad, 2008, p. 7). Em 1996, no entanto, esta visão sofreu uma importante modificação, com a criação do Plano Nacional de Qualificação do Trabalhador (Planfor) pelo MTE, através de recursos do Fundo de Amparo ao Trabalhador (FAT).

O objetivo deste plano era prover, anualmente, a partir de 1999, educação profissional para a qualificação ou requalificação de, no mínimo, $20 \%$ da população economicamente ativa $(\mathrm{PEA})^{2}$, democratizando, assim, o acesso dos indivíduos à educação profissional através de iniciativas públicas e gratuitas. A definição das políticas deveria ser feita de forma descentralizada no território, para que assim as necessidades de cada região pudessem ser preenchidas. Este objetivo, no entanto, sofreu algumas limitações devido à falta de informações em diversos municípios brasileiros. Os resultados do Planfor na década de 1990 foram, contudo, minimizados por dificuldades econômicas, como baixas taxas de crescimento do PIB e reestruturação produtiva, o que acentuou a flexibilização e a precarização do mercado de trabalho (Bulhões, 2004, p. 40-41). Atualmente, o MTE trabalha a qualificação profissional por meio do Plano Setorial de Qualificação (Planseq).

Ademais, a partir do ano 2000, as políticas públicas destinadas à educação passaram por uma reestruturação, sendo incluídas no Plano de Desenvolvimento da Educação (PDE) em 2007. Este plano representou um rompimento com a maneira anterior de se pensar o ensino, criando políticas articuladas e sistêmicas para os diversos níveis e faces da educação no Brasil. O PDE, desenvolvido no âmbito do Ministério da Educação, representa para a educação profissional um maior esforço de expansão dos institutos federais de educação, ciência e tecnologia (IFET) por todo o território brasileiro, juntamente com uma maior organização dos cursos de graduação tecnológica, no intuito de produzir uma articulação mais forte com a educação formal (HADDAD, 2008).

\subsection{Formalização da teoria do capital humano}

Todo este esforço do governo federal em estimular a educação profissional dos indivíduos é amparado pela teoria econômica por meio da teoria do capital humano, que trata da relação entre produtividade e remuneração no mercado de trabalho, e tem seus pilares nos estudos de Jacob Mincer e Gary Becker.

(2) A PEA é definida pelo IBGE como os indivíduos acima de 10 anos, classificados como ocupados ou desocupados (mas que tomaram alguma providência para conseguir trabalho) na semana de referência da pesquisa (IBGE, 2009b). 
Becker assume que a remuneração do trabalhador varia de acordo com a sua produtividade, a qual, por sua vez, altera-se conforme uma série de fatores, dentre eles o tempo e a qualidade da educação formal, treinamentos no trabalho, experiência no trabalho e condições de saúde. A partir de observações empíricas, Becker (1993) e Mincer (2009) mostram que a relação direta entre remuneração e anos de educação formal é fraca.

A variação na produtividade decorre de investimentos em capital humano, que podem ser realizados através de políticas públicas, iniciativas de empresas particulares ou por demanda individual do próprio trabalhador. Dentre estes investimentos estão a educação formal e treinamentos on-the-job. Antes de diferenciar ambos, porém, é importante estabelecer as hipóteses básicas do modelo de oferta de trabalho neoclássico, arcabouço teórico no qual se baseia a teoria do capital humano.

Mincer (2009) aponta que investimentos em educação formal ocupam certo tempo e, logo, tais investimentos têm, além de seu próprio custo, direto e indireto (livros, mensalidades, transporte até a escola etc.), um custo de oportunidade relativo ao tempo empregado nesta atividade quando não se está trabalhando. Desta forma, o investimento em educação formal só é feito aumentando-se o valor presente da renda futura ${ }^{3}$.

Raciocínio semelhante se aplica ao treinamento voltado para o mercado de trabalho, mas, nesta situação, o trabalhador se qualifica enquanto está trabalhando. Claramente aqui também haverá um custo, caso contrário, a demanda por treinamento seria infinita. Este custo inclui os materiais utilizados, o pagamento de professores, o esforço do trabalhar, entre outros fatores. Identifica-se dois tipos de treinamento: o geral e o específico. Enquanto aquele aumenta a produtividade do indivíduo frente a vários empregadores, este aumenta a produtividade do trabalhador apenas em relação à firma na qual este está empregado (envolve, por exemplo, a capacitação para operar uma máquina específica daquela firma) (Becker, 1993, p.31).

Esta divisão entre treinamento geral e específico, como alertado pelo próprio Becker (1993, p. 49), é por demais rígida e muitas vezes é difícil qualificar certas habilidades como de interesse de apenas uma única firma ou de toda uma indústria. Consequentemente, é possível questionar o financiamento integral de cursos de capacitação pela empresa empregadora (Clark; Fahr, 2002). Leuven e outros (2002) refutam esta hipótese por meio de constatações empíricas de

(3) Este argumento é reforçado por Becker, que assume que tais investimentos em educação são feitos apenas se aumentarem a produtividade do trabalhador. Como pressupõe-se que a remuneração está diretamente relacionada à produtividade, a escolha em investir em educação no presente depende da expectativa de maiores ganhos salariais no futuro (Cahuc; Zylberberg, 2004). 
empresas que arcam com grande parte dos custos de treinamentos ditos gerais. Para estes autores, a hipótese tradicional de que as firmas não investiriam em capacitações amplas e subinvestiriam em capacitações especializadas devido à antecipação de um comportamento oportunista dos trabalhadores não é verificada devido a características não consideradas dos trabalhadores, como senso de justiça e reciprocidade (Leuven et al., 2002, p. 5).

Outros autores justificam esta constatação empírica através de falhas de mercado que criam um cenário de compressão dos salários em relação à produtividade. Bhaskar e Holden (2002) apresentam um modelo matemático que refuta a existência de equilíbrio quando as empresas financiam totalmente treinamentos ditos específicos. Segundo estes autores, as firmas ofereceriam o treinamento aos trabalhadores em situações em que a distribuição de salários estivesse comprimida a ponto de não permitir à firma diferenciar o pagamento entre indivíduos com diferentes habilidades que não fossem diretamente relacionadas a treinamentos $(2002$, p. 18).

\subsection{Produtividade e diferencial de salários}

Ao se estudar educação profissional, uma das principais questões que se coloca é em relação ao retorno do trabalhador que investe neste tipo de qualificação: existe um diferencial de salário relevante entre este grupo de trabalhadores e os demais? Como citado anteriormente, mudanças recentes no modo de produção, provocadas pela informatização generalizada, exigem uma qualificação diferenciada do trabalhador, o que vem se refletindo na busca individual por cursos que atendam este fim além do ambiente da empresa.

Ademais, espera-se que trabalhadores mais qualificados sejam mais produtivos e que, portanto, sejam remunerados com salários mais altos, correspondentes à sua produtividade marginal. Os efeitos do progresso tecnológico sobre o mercado de trabalho são estudados por vários economistas, principalmente no que concerne à relação entre tecnologia e diferenciais de salário. A teoria que considera o avanço tecnológico responsável pelo aumento da demanda por trabalhadores mais qualificados, o que aprofundou o hiato entre salários dos trabalhadores, é denominada Skill Biased Technical Change (SBTC). Segundo esta abordagem:

More direct evidence also suggests that (broadly interpreted) skill-biased technological change is an important source of shifts in relative labor demand. Much econometric and case study evidence indicates that the relative utilization of more-skilled workers is positively correlated with capital intensity and the implementation of new technologies both across industries and across plants within detailed industries (Katz, 1998, p. 86). 
Há ainda algumas teorias que apontam outras razões para o aumento no gap salarial a partir da década de 1970. A hipótese de Card e Dinardi (2002), por exemplo, mostra a insuficiência da SBTC para explicar este fenômeno. Segundo estes autores, apesar da mudança tecnológica ser importante para explicar as mudanças no padrão salarial ocorridas a partir da década de 1970, é fundamental considerar outros aspectos institucionais, como relações de trabalho, piso salarial, salário de eficiência etc., além de reconhecer que as diferentes indústrias têm diferentes ritmos de implementação da tecnologia informatizada, o que faz com que a relação entre avanço tecnológico e diferenciais de salário não seja observada de maneira tão clara na década de 90 como o foi no início dos anos 80 .

Ainda que a relação entre tecnologia e diferencial de salário não seja consensual, a hipótese de que os retornos educacionais e de qualificação são positivos é considerada por todos os autores em questão. Logo, há espaço para outro tipo de debate, o qual discute a construção de habilidades pelos trabalhadores, a importância da família, da escola e da genética neste processo, além da a melhor idade e momento para se realizar investimentos públicos e privados em educação profissional.

Alguns autores argumentam que, quanto mais cedo for feito o investimento em educação, mais proveitoso este será, pois as capacitações posteriores serão mais exitosas ("skill begets skill"). Carneiro, Cunha e Heckman (2003) argumentam que a construção de habilidades é um processo que percorre todo o ciclo de vida, no qual famílias, firmas e escolas têm um papel fundamental. Em relação à importância de investir em qualificação precoce, Benzil, Hansen e Kristensen (2008) argumentam que educar crianças é mais efetivo para o desenvolvimento do que capacitar adultos despreparados, já que estes autores defendem a existência de uma complementaridade entre educação e treinamento.

Tal complementaridade pode ocorrer de duas formas: em primeiro lugar, pode-se avaliar que o acúmulo de habilidades reduz o custo de investir em outras habilidades posteriormente, o que significaria uma correlação positiva entre educação formal e qualificação posterior ao nível básico e possibilitaria a separação dos retornos salariais da educação e do treinamento, como numa equação de Mincer clássica ${ }^{4}$. A outra abordagem relativa ao acúmulo de habilidades trata os retornos salariais associados ao treinamento, para dado nível de habilidade idiossincrática, como dependente da educação formal adquirida. Assim, a equação salarial não mais poderia ser separável entre educação e treinamento, pois o retorno do treinamento seria maior para indivíduos com maior nível de escolaridade.

(4) A equação de salários de Mincer é dada por $\ln Y(s, x)=\alpha+\beta s+\not x+\delta x^{2}$, em que $\mathrm{Y}(\mathrm{s}, \mathrm{x})$ é a renda ajustada pelas horas de trabalho, $\mathrm{s}$ é anos de estudo e $\mathrm{x}$ é a experiência, sendo $\beta$ o coeficiente minceriano de educação (Mincer, 2009). 
Já em relação a investimentos em treinamentos e capacitações na idade adulta, o artigo de Carneiro, Cunha e Heckman, como mencionado anteriormente, aponta que adultos com baixo nível de habilidades cognitivas e não cognitivas trarão menores retornos à educação e treinamento quando comparado a adultos com maiores habilidades $(2004$, p. 6). De qualquer forma, por mais que a formação de habilidades (cognitivas ou não) seja mais profícua durante a infância, ainda é possível aprimorá-la durante a idade adulta. No entanto, agir nesta fase pode ter altos custos para o governo e os retornos de tais investimentos tendem a ser baixos (2003, p. 17).

Severnini e Orellano (2010) evidenciam uma relação positiva entre ensino profissionalizante e rendimento do trabalho no Brasil. Tais autores dividem esse tipo de educação em: ensino profissional básico (o qual tem um impacto positivo sobre o rendimento em comparação com os que não têm essa formação) e ensino superior tecnológico (o qual apresenta impacto negativo sobre o rendimento em comparação com trabalhadores cuja formação no ensino superior não é tecnológica). No entanto, conforme destaque dos autores, estes impactos podem estar enviesados por características dos trabalhadores que decidem cursar educação profissional, e este efeito não é tratado nas estimações do impacto deste tipo de formação sobre os rendimentos.

O estudo aqui apresentado pretende complementar esta literatura utilizando informações sobre os trabalhadores no Brasil e recorrendo à correção de Heckman para atenuar problemas decorrentes de seleção amostral, pois nem todos os trabalhadores vivenciam a experiência de educação profissional.

\section{Metodologia}

\subsection{Fonte de informação}

A base de dados utilizada é a PNAD de 2007, incluindo seu suplemento com características adicionais da educação de jovens e adultos. A PNAD é uma pesquisa anual realizada pelo IBGE de forma amostral em todas as unidades da federação no Brasil e, além das informações coletadas anualmente referentes a características dos domicílios e de seus moradores, contém um suplemento dedicado a certo tema específico. O suplemento de 2007 traz informações sobre o acesso e a formação da população em diversos setores da educação (como qualificação profissional, técnico de nível médio e graduação tecnológica) e foi realizado em parceria com o Ministério da Educação. Para a estimação do modelo, são utilizadas informações contidas no suplemento referentes à qualificação profissional e à graduação tecnológica de pessoas que frequentam e frequentaram tais modalidades. Além disso, as características dos moradores são utilizadas para traçar o perfil do brasileiro que faz formação profissional. Para tal, foram selecionadas as variáveis descritas no Quadro1. 
Quadro 1

Variáveis selecionadas

\begin{tabular}{|c|c|c|}
\hline Variáveis & Descrição & Justificativa \\
\hline Sexo & $\begin{array}{l}\text { Refere-se ao sexo do indivíduo } \\
\text { (masculino ou feminino). Homens } \\
\text { assumem o valor um, e mulheres, zero. }\end{array}$ & $\begin{array}{l}\text { Relevante para informar se há } \\
\text { diferenças por sexo na } \\
\text { qualificação. }\end{array}$ \\
\hline Cor & $\begin{array}{l}\text { Corresponde à autoclassificação do } \\
\text { entrevistado em uma das cinco } \\
\text { categorias: branco, preto, amarelo, } \\
\text { pardo e indígena. Na estimação, serão } \\
\text { usados dois grupos: brancos e amarelos } \\
\text { (assumem o valor um), e pretos e } \\
\text { pardos (assumem o valor zero). }\end{array}$ & $\begin{array}{l}\text { Relevante para informar se há } \\
\text { diferenças por cor na } \\
\text { qualificação, isto é, se pretos e } \\
\text { pardos estão sub-representadados } \\
\text { na qualificação assim como estão } \\
\text { na educação do ensino médio e } \\
\text { superior. }\end{array}$ \\
\hline Idade & $\begin{array}{l}\text { Calculada em anos na data de } \\
\text { referência. }\end{array}$ & $\begin{array}{l}\text { Relevante para informar se a } \\
\text { experiência influi na decisão de } \\
\text { qualificação. }\end{array}$ \\
\hline $\begin{array}{l}\text { Condição na } \\
\text { família }\end{array}$ & $\begin{array}{l}\text { Descreve a função de cada pessoa na } \\
\text { família, de acordo com as seguintes } \\
\text { categorias: Pessoa de referência (chefe), } \\
\text { que assume o valor um, e Cônjuge e } \\
\text { Filho, que assumem o valor zero. }\end{array}$ & $\begin{array}{l}\text { Relevante para informar se os } \\
\text { chefes estão mais sujeitos a } \\
\text { qualificação para melhorar a } \\
\text { inserção no mercado de trabalho } \\
\text { e, com isso, ampliar a renda } \\
\text { familiar. Ou, se são os filhos, por } \\
\text { serem mais jovens que estão mais } \\
\text { interessados, haja vista as novas } \\
\text { exigências do mercado. }\end{array}$ \\
\hline Anos de estudo & $\begin{array}{l}\text { Corresponde à escolaridade formal do } \\
\text { entrevistado, de acordo com a última } \\
\text { série ou grau finalizado. }\end{array}$ & $\begin{array}{l}\text { Relevante para informar se há } \\
\text { interação entre educação formal e } \\
\text { qualificação. }\end{array}$ \\
\hline $\begin{array}{l}\text { Condição de } \\
\text { atividade }\end{array}$ & $\begin{array}{l}\text { Informa se o indivíduo era } \\
\text { economicamente ativo na semana de } \\
\text { referência, assumindo o valor um, e, } \\
\text { caso contrário, o valor zero. }\end{array}$ & $\begin{array}{l}\text { Relevante para informar como o } \\
\text { fato de o indivíduo fazer parte da } \\
\text { população economicamente ativa } \\
\text { afeta a probabilidade deste cursar } \\
\text { educação profissional. }\end{array}$ \\
\hline $\begin{array}{l}\text { Grupamento da } \\
\text { atividade } \\
\text { principal }\end{array}$ & $\begin{array}{l}\text { Informa a que ramo pertence a atividade } \\
\text { exercida pelo indivíduo: agrícola, } \\
\text { industrial (atividades industriais e } \\
\text { indústria de transformação), construção } \\
\text { civil e serviços (construção, comércio e } \\
\text { reparação, alojamento e alimentação, } \\
\text { transporte, armazenagem en e } \\
\text { comunicação, administração pública, } \\
\text { educação, saúde e serviços sociais, } \\
\text { serviços domésticos, outros serviços } \\
\text { coletivos, sociais e pessoais) ou outras } \\
\text { atividades. }\end{array}$ & $\begin{array}{l}\text { Relevante para informar como o } \\
\text { ramo de atividade afeta a } \\
\text { remuneração do indivíduo. }\end{array}$ \\
\hline Grande região & $\begin{array}{l}\text { Informa se o domicílio está localizado } \\
\text { na região Norte, Nordeste, Sudeste, } \\
\text { Centro-Oeste ou Sul do Brasil. }\end{array}$ & $\begin{array}{l}\text { Relevante para informar como a } \\
\text { grande região em que está } \\
\text { localizado o domicílio do } \\
\text { indivíduo afeta sua probabilidade } \\
\text { de se qualificar. }\end{array}$ \\
\hline
\end{tabular}




\subsection{Metodologia formal}

O perfil dos indivíduos trabalhadores brasileiros e a existência de um diferencial de rendimentos para quem faz formação profissional são analisados por meio de um método que busca resolver o problema de seleção amostral, já que o treinamento não é observado para toda a população, mas apenas para os que o fizeram. $\mathrm{O}$ indivíduo que conclui o treinamento vai receber um salário referente a essa qualificação. Como não experimentou o fato de não ter o treinamento, o valor presente do benefício de não treinar grau vai ser obtido a partir de outro indivíduo que, realmente, não treinou. $\mathrm{O}$ ideal seria comparar o salário observado depois de concluído o treinamento com o salário desse mesmo indivíduo caso ele não houvesse treinado. A amostra de treinados é, portanto, uma amostra "selecionada" da população de ocupados, uma vez que há correlação espúria entre os salários dos que possuem treinamento e o termo aleatório. Além dessa seleção, temos uma outra que é a inserção no mercado de trabalho.

Para atenuar tais problemas de seletividade, recorremos à estratégia de identificação proposta por Heckman. Trata-se da estimação por máxima verossimilhança em dois estágios. No primeiro, a equação de seleção, avalia-se a probabilidade do indivíduo se inserir no mercado de trabalho, onde permanecer estudando após a conclusão de ensino médio é incluída como variável proxy para a possibilidade de cursar educação profissional, seguida por uma equação de rendimentos, tendo o logaritmo do rendimento/hora como variável dependente e uma das covariadas é ter concluído algum curso de educação profissional.

A equação de seleção é definida pela expressão:

ocupado $=\beta_{0}+\beta_{1} \log$ dorendimentodomicliarpercapita $+\beta_{2}$ continuoustudardepaismedio + $\beta_{3}$ condfam $+\beta_{4}^{\text {norte }++\beta}{ }_{5}^{\text {sul }+\beta_{6} \text { nordeste }+\beta_{7} \text { co }+\beta_{8}+u}$

A equação de rendimentos corrigida por viés de seleção é, assim, definida:

$$
\begin{aligned}
& \ln Y_{i}=C+\beta_{1} \text { eprof }_{i}+\beta 2 \text { Sexo }_{i}+\beta 3 \text { Cor }_{i}+\beta 4 i d a d e_{i}+\beta 5 \text { idade }_{i}^{2}+ \\
& \beta 6 \text { escolaridade }{ }_{i}+\beta_{7} \text { agricola }_{i}+\beta 8 \text { setor }+\lambda_{i}+\varepsilon
\end{aligned}
$$

\section{Resultados}

\subsection{Análise descritiva}

A análise dos microdados coletados da PNAD 2007 permite traçar um perfil dos brasileiros que frequentam algum curso de educação profissional. Notase, primeiramente, que apenas $3,8 \%$ dos entrevistados entre dez e 65 anos

(5) Apenas os indivíduos maiores de dez anos responderam ao suplemento da PNAD. Além disso, optouse por não utilizar o corte tradicional de idade (acima de 18 anos), pois dos 11905 indivíduos que cursavam educação profissional, 4018 tinham entre dez e 18 anos; assim, manter este grupo na amostra foi de extrema importância para a análise. 
frequentam essa modalidade de ensino ${ }^{6}$. Apesar deste número ainda ser pequeno, a pesquisa aponta que, além destes, $18,6 \%$ dos indivíduos haviam frequentado anteriormente tais cursos, totalizando 35,6 milhões de pessoas $(22,4 \%$ do grupo que respondeu ao questionário) que usufruíram algum tipo de educação profissional. Dentre os que nunca frequentaram esta categoria de ensino, a maioria argumenta falta de interesse pelos mesmos. A ausência de vagas é apontada como motivo apenas por $0,5 \%$ dos entrevistados, como mostra a Tabela 1 abaixo:

Tabela 1

Motivo principal para não frequentar educação profissional segundo a PNAD 2007

\begin{tabular}{lcc}
\hline Motivo para não frequentar educação profissional & Freq. & Percent \\
\hline Falta escola com curso de educação profissional na região. & 9.789 .833 & 7,46 \\
Falta de vaga no curso & 659.955 & 0,5 \\
Não havia o curso desejado & 2.226 .213 & 1,7 \\
Falta de recursos, pois a escola é paga & 17.998 .917 & 13,71 \\
Não há interesse & 88.300 .333 & 67,27 \\
Outro & 12.295 .612 & 9,37 \\
\hline Total & 131.270 .863 & 100 \\
\hline
\end{tabular}

Fonte: PNAD (2007). Elaboração própria.

Aos que respondem frequentar ou já ter frequentado algum curso de educação profissional, o questionário progride dividindo este tipo de ensino em três segmentos, como foi prescrito pela LDB em 1996: qualificação profissional, técnico de nível médio e graduação tecnologia. Na época da pesquisa, entre os que frequentavam, a grande maioria dos indivíduos frequentava algum tipo de qualificação profissional $(81,03 \%)$; o segundo curso mais requisitado era o técnico de nível médio $(17,46 \%)$, e a graduação tecnológica era frequentada por apenas $1,51 \%$ dos entrevistados.

Seguindo a tendência de informatização e mecanização dos processos em empresas e indústrias, a demanda por cursos de informática se destaca no ramo de qualificação profissional. Como mostra a Tabela 2, 36,07\% dos indivíduos se capacita nesta área, sendo comércio e gestão outra área de destaque $(12,59 \%)$.

Já entre os técnicos de nível médio, os cursos na área de saúde merecem destaque, sendo frequentados por 29,23\% dos alunos, seguidos pelos cursos na área industrial. A área de informática também recebe uma parcela significativa de alunos, o que fortalece a hipótese de especialização voltada para as demandas do mercado (Tabela 3):

(6) A amostra tinha, inicialmente, 399964 observações. Após a seleção da faixa etária a ser trabalhada, foram excluídos 91.110 indivíduos, restando 308854, sem expansão amostral. 
Tabela 2

Composição por área dos cursos de qualificação profissional

\begin{tabular}{lc}
\hline Área de qualificação profissional & Freq. \\
\hline Saúde e bem estar social & $7,48 \%$ \\
Informática & $36,07 \%$ \\
Construção civil & $2,42 \%$ \\
Indústria e manutenção & $14,28 \%$ \\
Estética e imagem pessoal & $5,81 \%$ \\
Comércio e gestão & $12,59 \%$ \\
Outra & $21,35 \%$ \\
\hline Total & $100,00 \%$ \\
\hline
\end{tabular}

Fonte: PNAD (2007). Elaboração própria.

Tabela 3

Composição por área dos cursos técnicos de nível médio

\begin{tabular}{ll}
\hline Área técnico nível médio & Freq. \\
\hline Saúde & $29,23 \%$ \\
Indústria & $21,51 \%$ \\
Gestão & $10,73 \%$ \\
Informática & $13,29 \%$ \\
Agropecuária & $4,23 \%$ \\
Outra & $21,01 \%$ \\
\hline Total & $100,00 \%$ \\
\hline
\end{tabular}

Fonte: PNAD (2007). Elaboração própria.

Entre os que cursam graduação tecnológica, a área mais procurada é a de comércio, gestão e turismo, o que mostra que este setor empreendedor está em ascensão, como já havia sido destacado pelas escolhas dos cursos de qualificação profissional. A área de informática, ainda que apresente uma parcela relevante da demanda por graduação tecnológica, já não ocupa as primeiras posições como observado nas demais categorias de educação profissional, o que se verifica na Tabela abaixo.

Tabela 4

Composição por área dos cursos de graduação tecnológica

\begin{tabular}{ll}
\hline Área de graduação tecnológica & \\
\hline Artes, comunicação e design & $1,89 \%$ \\
Saúde e meio ambiente & $17,38 \%$ \\
Comércio, gestão e turismo. & $23,99 \%$ \\
Construção civil, geomática e transportes. & $5,87 \%$ \\
Indústria, química e mineração. & $15,81 \%$ \\
Informática e telecomunicações. & $11,12 \%$ \\
Outra & $23,94 \%$ \\
\hline Total & $100,00 \%$ \\
\hline
\end{tabular}


Ainda na análise segundo categoria de educação profissional, nota-se que, nos três casos, a maioria dos concluintes dos cursos trabalha, ou já trabalhou, na área de especialização. Esta porcentagem é maior para os que fizeram graduação tecnológica $(77,30 \%)$, seguida pelos técnicos de nível médio $(65,08 \%)$ e pelos que cursaram qualificação profissional $(55,59 \%)$.

Tabela 5

Indivíduos que trabalham ou já trabalharam na área de formação

\begin{tabular}{lcc}
\hline Trabalha na área de formação & Sim & Não \\
\hline Qualif. Profissional & $55,58 \%$ & $44,42 \%$ \\
Técnico nível médio & $65,08 \%$ & $34,92 \%$ \\
Graduação tecnológica & $77,30 \%$ & $22,70 \%$ \\
\hline
\end{tabular}

No Brasil, a maior parte dos indivíduos que cursa ou havia cursado educação profissional está no sudeste $(47,38 \%)$, o que repercute a maior oferta de empregos nessa região e a maior demanda dos empregadores por trabalhadores qualificados. Há ainda uma significativa parcela dos brasileiros que frequentam ou frequentaram este tipo de ensino que reside no nordeste $(20,35 \%)$ e no sul $(18,83 \%)$, como é retratado pelo Gráfico 1 abaixo:

Gráfico 1

Brasileiros que frequentam ou frequentaram educação profissional segundo região de residência

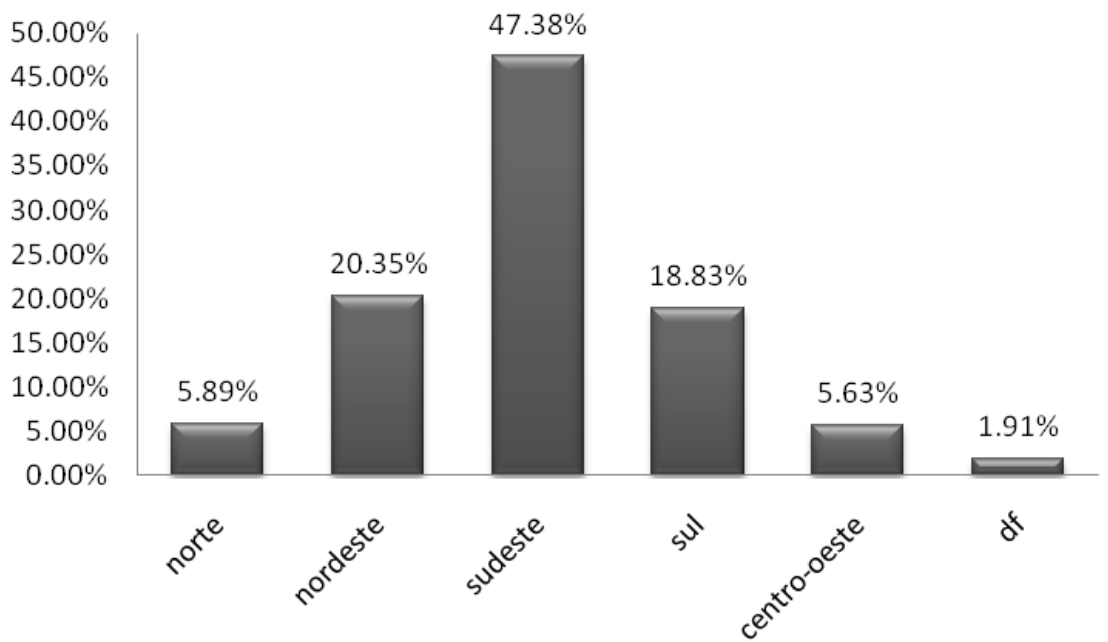

Fonte: PNAD (2007). Elaboração própria.

Em relação à condição de ocupação, do Gráfico 2, apreende-se que, entre os ocupados, aqueles que cursavam na semana de referência e os que haviam 
cursado anteriormente educação profissional, a proporção (60\%) é maior do que entre os que nunca frequentaram tal qualificação:

\section{Gráfico 2}

Relação de brasileiros ocupados que cursam ou haviam cursado educação profissional

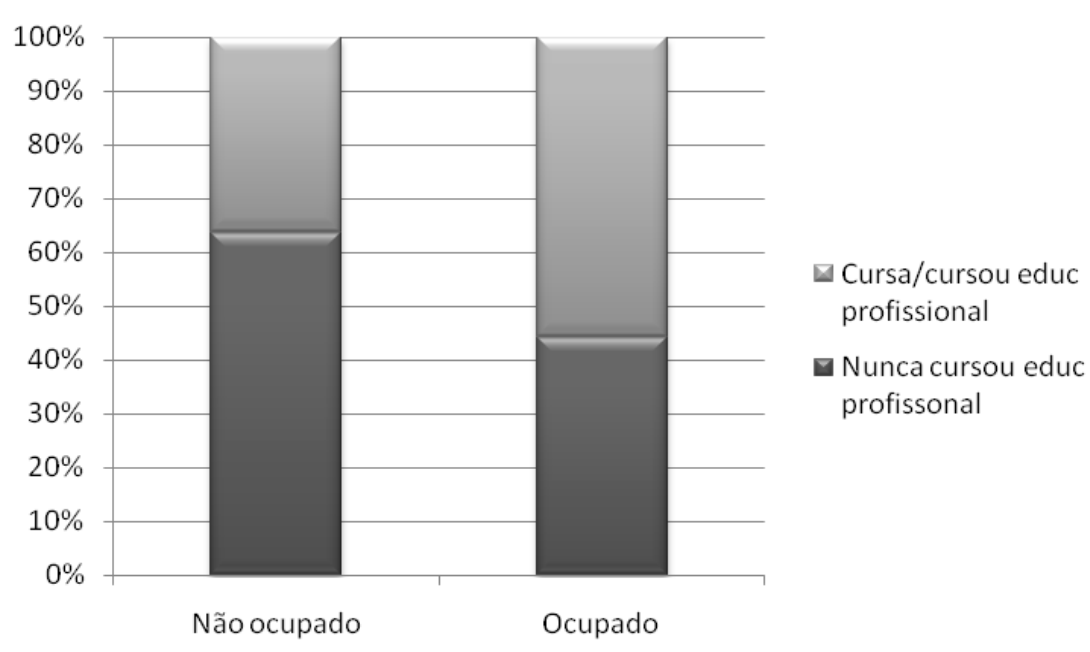

Fonte: PNAD (2007). Elaboração própria.

No entanto, a Tabela 6 mostra que, considerando apenas os que cursavam este tipo de ensino no momento da pesquisa, a proporção de desocupados $(7,53 \%)$ é superior a de ocupados $(3,67 \%)$ :

Tabela 6

Proporção dos brasileiros ocupados que cursavam educação profissional na semana da pesquisa

\begin{tabular}{lcc}
\hline Cursa educ. prof. & Não ocupado & Ocupado \\
\hline Não & $96,33 \%$ & $92,47 \%$ \\
Sim & $3,67 \%$ & $7,53 \%$ \\
\hline Total & $100,00 \%$ & $100,00 \%$ \\
\hline
\end{tabular}

Em relação ao sexo, as mulheres são as que mais frequentam cursos de educação profissional, tanto em proporção (4,31\% das mulheres contra 3,78\% dos homens) quanto em números absolutos (3,023 milhões de mulheres contra 2,515 milhões de homens). Ao introduzir a separação por tipo de curso, os resultados por sexo são os seguintes: 
Tabela 7

Relação dos brasileiros que cursam educação profissional segregados por sexo

\begin{tabular}{lcc}
\hline Sexo & Feminino & Masculino \\
\hline Qualificação profissional & $81,48 \%$ & $80,62 \%$ \\
Técnico nível médio & $17,91 \%$ & $18,53 \%$ \\
Graduação tecnológica & $0,60 \%$ & $0,85 \%$ \\
\hline Total & $100,00 \%$ & $100,00 \%$ \\
\hline
\end{tabular}

Fonte: PNAD (2007). Elaboração própria.

Como mostra a Tabela 7, não há um viés de gênero no que diz respeito ao tipo de curso procurado, mas observa-se uma procura um pouco maior de mulheres por qualificação profissional, enquanto há mais homens cursando o técnico de nível médio.

Já em relação ao tipo de curso procurado, destacam-se diferenças entre os sexos: há um número maior de mulheres que buscam especializar-se em áreas relacionadas à saúde e bem-estar e à estética, enquanto os homens preferem áreas mais técnicas, como indústria e construção civil, como mostra a Tabela 8. Tal composição reflete uma segregação ocupacional já existente no mercado de trabalho. Esta divisão é reafirmada pela análise dos cursos técnicos de nível médio e a graduação tecnológica (Tabelas 9 e 10, respectivamente). Nesta, nota-se que as mulheres representam a totalidade dos que se especializam em temas relacionados a artes, comunicação e design, enquanto os homens representam a maioria dos que se graduam em construção civil, geomática e transportes. Já no técnico de nível médio, as mulheres são as que mais frequentam cursos que têm a saúde como temática, enquanto os homens preferem especializar-se nas áreas da indústria e da agropecuária.

Tabela 8

Área do curso de qualificação profissional segundo o sexo do indivíduo

\begin{tabular}{lcc}
\hline Área qualif. profissional & Feminino & Masculino \\
\hline Saúde e bem estar social. & $76,45 \%$ & $23,55 \%$ \\
Informática & $54,57 \%$ & $45,43 \%$ \\
Construção civil & $6,44 \%$ & $93,56 \%$ \\
Indústria e manutenção & $16,39 \%$ & $83,61 \%$ \\
Estética e imagem pessoal & $91,36 \%$ & $8,64 \%$ \\
Comércio e gestão & $61,70 \%$ & $38,30 \%$ \\
Outra & $53,59 \%$ & $46,41 \%$ \\
\hline Total & $52,50 \%$ & $47,50 \%$ \\
\hline
\end{tabular}


Tabela 9

Área do curso técnico de nível médio segundo o sexo do indivíduo

\begin{tabular}{lcc}
\hline Área técnico nível médio & Feminino & Masculino \\
\hline Saúde & $80,56 \%$ & $19,44 \%$ \\
Indústria & $15,24 \%$ & $84,76 \%$ \\
Gestão & $57,91 \%$ & $42,09 \%$ \\
Informática & $34,27 \%$ & $65,73 \%$ \\
Agropecuária & $15,73 \%$ & $84,27 \%$ \\
Outra & $61,11 \%$ & $38,89 \%$ \\
\hline Total & $51,39 \%$ & $48,61 \%$ \\
\hline
\end{tabular}

Tabela 10

Área do curso técnico de graduação tecnológica segundo o sexo do indivíduo

\begin{tabular}{lcc}
\hline Área graduação tecnológica & Feminino & Masculino \\
\hline Artes, comunicação e design & $62,82 \%$ & $37,18 \%$ \\
Saúde e meio ambiente & $53,37 \%$ & $46,63 \%$ \\
Comércio, gestão e turismo & $55,13 \%$ & $44,87 \%$ \\
Construção civil, geomática e & $24,48 \%$ & $75,52 \%$ \\
transportes & $20,27 \%$ & $79,73 \%$ \\
Indústria, química e mineração & $28,60 \%$ & $71,40 \%$ \\
Informática e telecomunicações & $55,48 \%$ & $44,52 \%$ \\
Outra & $43,85 \%$ & $56,15 \%$ \\
\hline Total & & \\
\hline
\end{tabular}

No tocante à distribuição por cor declarada ${ }^{7}$, observa-se que há um número maior de brancos e amarelos que frequentam educação profissional. Proporcionalmente, $4,46 \%$ dos brancos e amarelos, contra 3,64\% dos pretos e pardos, cursam este tipo de ensino. Verifica-se, entretanto, que a diferença não é tão significativa. O Gráfico 3 traça uma relação entre anos de estudo ${ }^{8}$ separados por categorias de cor e porcentagem da população naquela faixa de anos de estudo dos que frequentam educação profissional:

(7) A variável cor foi agrupada nas categorias brancos e amarelos, pretos e pardos. Os indivíduos que se declararam indígenas e os sem declaração foram excluídos da amostra (1170 observações) por não representarem uma parcela significativa dos que cursam educação profissional.

(8) Foram excluídos da amostra aqueles que não declararam anos de estudo, o que reduziu a amostra em 1459 observações. 
Gráfico 3

Relação dos brasileiros que cursam ou cursaram educação profissional segundo cor e anos de estudo

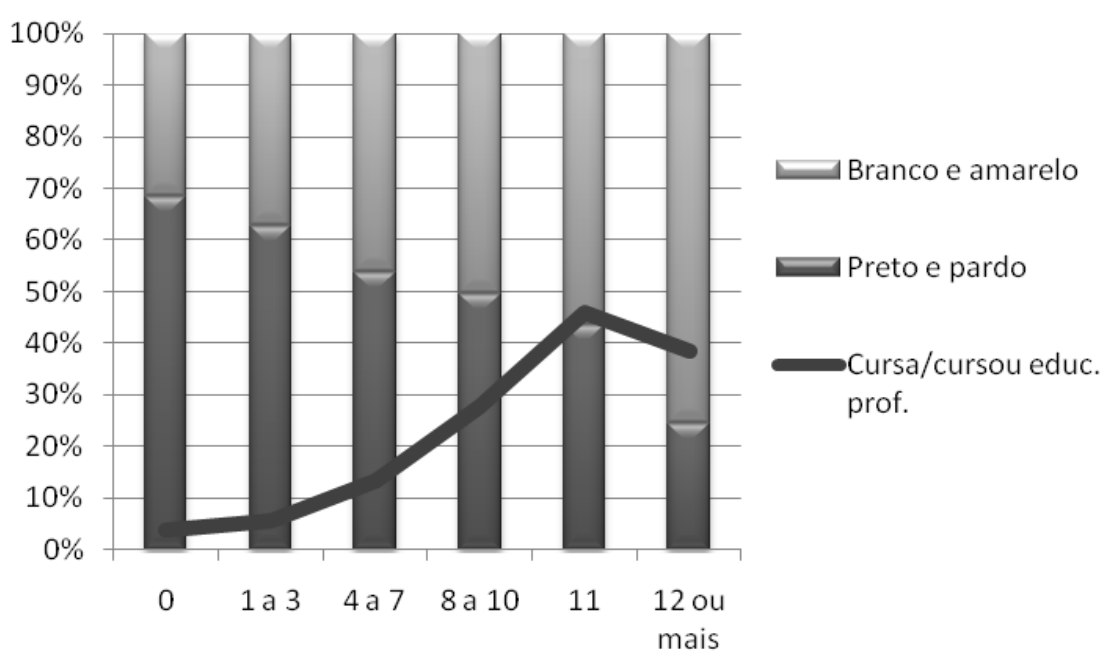

Fonte: PNAD (2007). Elaboração própria.

Em primeiro lugar, o gráfico mostra que a proporção de pretos e pardos declina quando aumenta os anos de educação formal dos indivíduos, fato já conhecido no Brasil. Em segundo lugar, observa-se uma relação monotônica crescente entre educação profissional e formal até a conclusão do Ensino Médio, ou seja, onze anos de estudo.

A Tabela 11 abaixo mostra a composição de cada curso de educação profissional segundo os anos de estudo dos indivíduos frequentadores:

Tabela 11

Frequência dos tipos de curso de educação profissional segundo anos de estudo do indivíduo

\begin{tabular}{lccccccc}
\hline Anos de estudo & 0 & 1 a 3 & 4 a 7 & 8 a 10 & 11 & 12 ou mais & Total \\
\hline Qualificação profissional & $1,46 \%$ & $3,60 \%$ & $20,15 \%$ & $23,91 \%$ & $35,64 \%$ & $15,24 \%$ & $100,00 \%$ \\
Técnico nível médio & $0,01 \%$ & $0,01 \%$ & $0,00 \%$ & $7,58 \%$ & $61,21 \%$ & $31,19 \%$ & $100,00 \%$ \\
Graduação tecnológica & $0,00 \%$ & $0,00 \%$ & $0,00 \%$ & $0,00 \%$ & $18,53 \%$ & $81,47 \%$ & $100,00 \%$ \\
\hline
\end{tabular}

Fonte: PNAD (2007). Elaboração própria.

Em relação à idade, como mostra o Gráfico 4, nota-se que, proporcionalmente, os indivíduos entre 19 e 24 anos e na faixa de 25 a 29 anos são os que mais frequentam educação profissional $(31,13$ e 30,61\%, respectivamente), e esta relação inversa entre idade e ensino profissional se mantém para toda a população, sendo os mais velhos, com idade entre 51 e 65 anos, os que menos cursam este tipo de ensino (apenas 1,44\%). 
Gráfico 4

Porcentagem de indivíduos que cursa ou cursou educação profissional segundo faixa etária

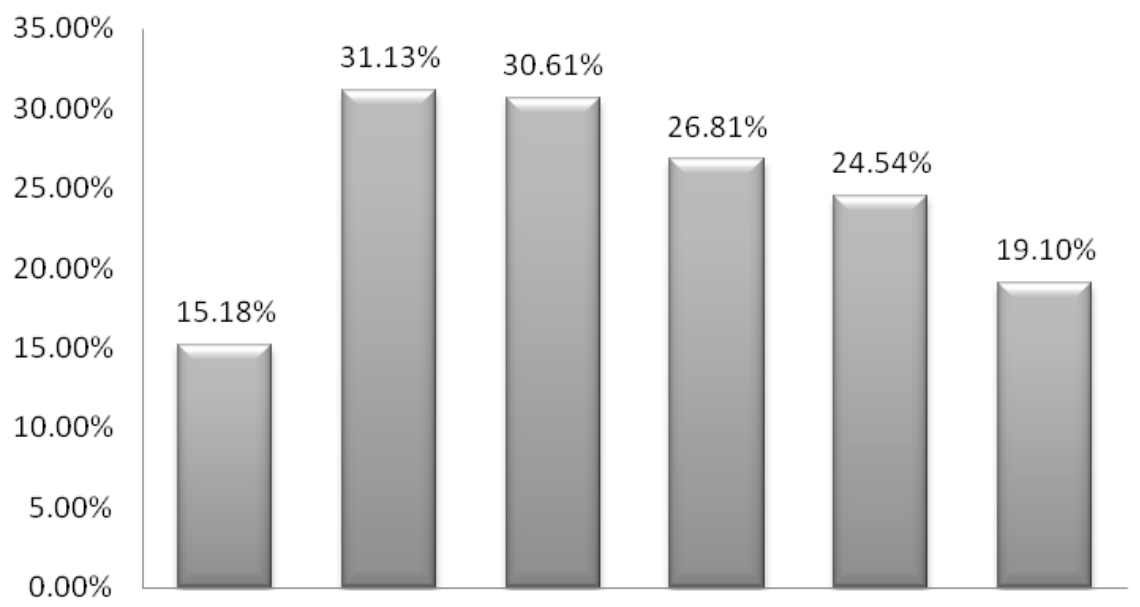

até 18 anos $19-24$ anos $25-29$ anos $30-34$ anos $41-50$ anos $51-65$ anos

Fonte: PNAD (2007). Elaboração própria.

A Tabela 12 confirma o que foi discutido anteriormente em relação aos anos de educação profissional. Supondo que exista certa regularidade entre a idade e a série correspondente na educação formal, nota-se que a qualificação profissional é muito forte entre os jovens, decaindo e, depois, voltando a elevar-se. Já o técnico de nível médio tem a maior parte de seus estudantes também entre os jovens, destacando-se a faixa de 19 a 24 anos. É também este grupo etário que ocupa a maior parte das cadeiras de graduação tecnológica, sendo que grande parte dos alunos tem entre 25 e 40 anos, o que está de acordo com as exigências para a entrada neste tipo de curso (ensino médio completo).

Tabela 12

Composição dos cursos de educação profissional segundo faixa etária dos indivíduos

\begin{tabular}{llllllll}
\hline Curso de educ profissional & $10-18$ & $19-24$ & $25-29$ & $30-34$ & $41-50$ & $51-65$ & Total \\
\hline Qualificação profissional & $15,56 \%$ & $17,96 \%$ & $13,69 \%$ & $23,53 \%$ & $16,71 \%$ & $12,55 \%$ & $100,00 \%$ \\
Técnico nível médio & $5,18 \%$ & $16,76 \%$ & $16,57 \%$ & $27,48 \%$ & $20,84 \%$ & $13,17 \%$ & $100,00 \%$ \\
Graduação tecnológica & $2,32 \%$ & $20,20 \%$ & $20,98 \%$ & $31,56 \%$ & $16,36 \%$ & $8,58 \%$ & $100,00 \%$ \\
\hline Total & $13,57 \%$ & $17,76 \%$ & $14,26 \%$ & $24,31 \%$ & $17,46 \%$ & $12,64 \%$ & $100,00 \%$ \\
\hline
\end{tabular}

Fonte: PNAD (2007). Elaboração própria.

Outra investigação interessante diz respeito à condição na família do indivíduo que cursa educação profissional. A Tabela 13 mostra os dados da PNAD sobre esta relação: 
Tabela 13

Porcentagem de brasileiros que cursam educação profissional segundo condição na família

\begin{tabular}{lccc}
\hline Cursa ou cursou educação profissional & Cônjuge ou filho & Chefe & Total \\
\hline Não & 77,39 & 74,28 & 76,22 \\
Sim & 22,61 & 25,72 & 23,78 \\
\hline Total & 100 & 100 & 100 \\
\hline
\end{tabular}

Fonte: PNAD (2007). Elaboração própria.

Há uma proporção maior de indivíduos que não são chefes e que cursam educação profissional, o que se deve, em primeiro lugar, aos filhos, que representam a grande parcela dos que frequentam este tipo de ensino. Além disso, não há relação direta entre posição ocupada na família e anos de estudo, enquanto observa-se que a proporção de chefes aumenta com a idade.

Em relação à ocupação, apenas 3,99\% dos ocupados cursavam educação profissional, enquanto para os desocupados este número era maior, chegando a $4,17 \%$ destes indivíduos. Já quando se considera o número absoluto de indivíduos ocupados cursando este tipo de ensino, nota-se que este supera o de desocupados (3,6 milhões contra 1,9 milhões).

O Gráfico 5 mostra a composição dos cursos de educação profissional segundo a condição de ocupação do indivíduo. Nota-se que os cursos de qualificação profissional são mais procurados pelos desocupados, enquanto os cursos técnicos de nível médio e graduação tecnológica são alvo de ocupados. Uma justificativa para este fato é a menor extensão dos cursos de qualificação, que podem durar apenas algumas semanas, enquanto os outros cursos duram de dois a três anos. Logo, indivíduos desocupados, que têm maior urgência para se qualificar e conseguir ocupação, preferem tal modalidade.

\section{Gráfico 5}

Composição segundo tipo de curso dos ocupados que cursavam educação profissional

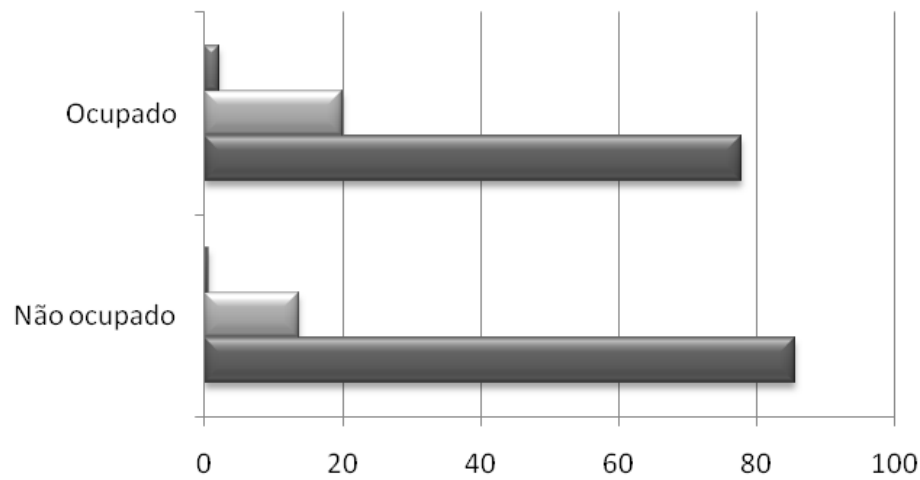

$\square$ graduação tecnológica

$\square$ técnico nível médio

qualificação profissional

Fonte: PNAD (2007). Elaboração própria. 
Dentre os ocupados, a porcentagem dos que cursam educação profissional é maior entre os que trabalham no setor formal ${ }^{9}(61,61 \%)$ do que entre os que estão na informalidade $(38,39 \%)$. Uma hipótese para esta verificação é de que a qualificação pode ajudar o indivíduo a ampliar seu rendimento. A Tabela 14, abaixo, mostra os indivíduos que cursaram educação profissional anteriormente e a porcentagem que se encontrava no setor formal na época da pesquisa.

Tabela 14

Porcentagem de indivíduos na formalidade que havia cursado educação profissional anteriormente

\begin{tabular}{lccc}
\hline Cursou educ profissional anteriormente & Informal & Formal & Total \\
\hline Não & 54,84 & 44,16 & 100 \\
Sim & 38,39 & 61,61 & 100 \\
\hline Total & 50,46 & 49,54 & 100 \\
\hline
\end{tabular}

Fonte: PNAD (2007). Elaboração própria.

Em relação à jornada de trabalho, observa-se que, entre aqueles que têm jornada semanal superior a 40h horas, há uma maior porcentagem de indivíduos que cursavam ou haviam cursado educação profissional, apesar desta diferença não ser muito acentuada, como mostra a Tabela 15 abaixo.

Tabela 15

Porcentagem de indivíduos que cursam educação profissional segundo o número de horas trabalhadas por semana no trabalho principal

\begin{tabular}{cccc}
\hline $\begin{array}{c}\text { Cursa/cursou } \\
\text { educ. prof. }\end{array}$ & $\begin{array}{c}\text { Jornada inferior a } \\
\text { 40h/semana }\end{array}$ & $\begin{array}{c}\text { Jornada igual ou } \\
\text { maior que } \\
\text { 40h/semana }\end{array}$ & Total \\
\hline Não & 77,97 & 72,7 & 76,22 \\
Sim & 22,03 & 27,3 & 23,78 \\
\hline Total & 100 & 100 & 100 \\
\hline
\end{tabular}

Fonte: PNAD (2007). Elaboração própria.

Já entre os grupamentos da atividade, verifica-se que trabalhadores no ramo da indústria são os que mais se qualificam, e os da agricultura, os que menos o fazem. Este resultado também já era esperado, tendo em vista que as áreas de educação profissional estão mais direcionadas para o desenvolvimento de habilidades utilizadas na indústria, comércio e serviços.

(9) Foram excluídos da amostra os trabalhadores na produção para o próprio consumo, os trabalhadores na construção para o próprio uso e os missings, o que retirou 106204 observações da amostra. 
Tabela 16

Porcentagem de indivíduos que cursam ou cursaram educação profissional segundo o grupamento da atividade

\begin{tabular}{lcccc}
\hline Cursa educação profissional & Agricultura & Indústria & $\begin{array}{c}\text { Const. civil e } \\
\text { serviços }\end{array}$ & Outras ativ. \\
\hline Não & 92,01 & 65,13 & 69,91 & 60,11 \\
Sim & 7,99 & 34,87 & 30,09 & 38,89 \\
\hline Total & 100 & 100 & 100 & 100 \\
\hline
\end{tabular}

Fonte: PNAD 2007. Elaboração própria.

Como foi mostrado pelas diversas tabelas e gráficos apresentados nesta análise descritiva, já é possível identificar certas características dos indivíduos que frequentam educação profissional no Brasil, em especial o curso de qualificação profissional, que possui o maior número de alunos inscritos. As mulheres são maioria na sala de aula. Além disso, nota-se uma predominância de indivíduos de cor branca e amarela assistindo a tais cursos, na maior parte dos casos com o ensino fundamental completo ${ }^{10}$. Este tipo de curso é frequentado majoritariamente por indivíduos jovens, com até 25 anos de idade. Foi verificada também uma superioridade, proporcionalmente, de indivíduos desocupados procurando este tipo de especialização.

\subsection{Resultados dos modelos}

Primeiramente, são apresentados os resultados do Heckman. Posteriormente, são analisados os resultados da regressão de MQO para o logaritmo do rendimento/hora ${ }^{11}$.

Os coeficientes estimados não podem ser interpretados diretamente. É possível, no entanto, avaliar o sinal dos coeficientes dos regressores e sua significância: a primeira variável (rendimento domiciliar per capita deduzido o rendimento do trabalhador) tem sinal positivo e é estatisticamente significativa a $1 \%$, o que indica que quanto maior a renda do domicilio maior a probabilidade do individuo participar do mercado de trabalho, permanecer estudando após a conclusão do Ensino Médio assim como ser chefe de família contribui para a inserção no mercado de trabalho. Em termos de grandes regiões, residindo no

(10) Adota-se, neste trabalho, a composição do ensino fundamental por oito séries, não considerando-se a recente inserção da nona série.

(11) A variável rendimento mensal, a partir da qual foi calculado o rendimento/hora, tinha inicialmente 210.940 observações missings, inativos, desocupados e aqueles que não declararam. Além destes, foram transformados em observações missings os rendimentos iguais a zero para que fosse possível trabalhar com o logaritmo do rendimento/hora. Após este processo, totalizaram-se 232.817 observações missings, o que correspondia a aproximadamente $58 \%$ da amostra total. 
Nordeste ou no Distrito Federal, reduz-se as chances do individuo de integrar o mercado de trabalho.

Tabela 17

Resultado da estimação Heckman e MQO

\begin{tabular}{|c|c|c|c|}
\hline Variáveis dependentes & Renda (em log) & Ocupado & MQO \\
\hline Educ. profissional & $\begin{array}{l}0.0100 * * * \\
(-0.00384)\end{array}$ & & $\begin{array}{l}0.0170 \\
(3.80)^{* *}\end{array}$ \\
\hline Sexo & $\begin{array}{l}0.108^{* * *} \\
(-0.0037)\end{array}$ & & $\begin{array}{l}0.2380 \\
(59.03)^{* *}\end{array}$ \\
\hline Raça & $\begin{array}{l}0.144 * * * \\
(-0.00352)\end{array}$ & & $\begin{array}{l}0.1810 \\
(47.87)^{* *}\end{array}$ \\
\hline Idade & $\begin{array}{l}0.0324 * * * \\
(-0.000865)\end{array}$ & & $\begin{array}{l}0.0540 \\
(54.93)^{* *}\end{array}$ \\
\hline Idade $^{2}$ & $\begin{array}{l}-0.000251^{* * *} \\
(-0.0000112)\end{array}$ & & $\begin{array}{l}0.0000 \\
(33.27)^{* *}\end{array}$ \\
\hline Anos de estudo & $\begin{array}{l}0.0803 * * * \\
(-0.000513)\end{array}$ & & $\begin{array}{l}0.0960 \\
(166.32)^{* *}\end{array}$ \\
\hline Agrícola & $\begin{array}{l}-0.119 * * * \\
(-0.00726)\end{array}$ & & $\begin{array}{l}-0.1240 \\
(15.63)^{* *}\end{array}$ \\
\hline Construção civil e serviços & $\begin{array}{l}0.0114^{* *} \\
(-0.00469)\end{array}$ & & $\begin{array}{l}-0.0080 \\
-1.5800\end{array}$ \\
\hline Outras atividades & $\begin{array}{l}0.0731^{* * *} \\
(-0.00717)\end{array}$ & & $\begin{array}{l}0.0900 \\
(10.92)^{* *}\end{array}$ \\
\hline constante MQO & & & $\begin{array}{l}-1.0130 \\
(54.34)^{* *}\end{array}$ \\
\hline Renda domiciliar pc (em log) & & $\begin{array}{l}0.291^{* * *} \\
(-0.00341)\end{array}$ & \\
\hline Continuou estudos após o ensino médio & & $\begin{array}{l}0.476 * * * \\
(-0.0105)\end{array}$ & \\
\hline Condição na família & & $\begin{array}{l}1.060 * * * \\
(-0.00601)\end{array}$ & \\
\hline Norte & & $\begin{array}{r}0.00145 \\
(-0.00942)\end{array}$ & \\
\hline Sul & & $\begin{array}{l}0.0494 * * * \\
(-0.0088)\end{array}$ & \\
\hline Nordeste & & $\begin{array}{l}-0.0471^{* * *} \\
(-0.0075)\end{array}$ & \\
\hline Centro-oeste & & $\begin{array}{l}0.0705^{* * *} \\
(-0.011)\end{array}$ & \\
\hline Distrito Federal & & $\begin{array}{l}-0.130^{* * *} \\
(-0.0175)\end{array}$ & \\
\hline Inverso da Razão de Mills & & & $\begin{array}{l}-0.722^{* * *} \\
(-0.00706)\end{array}$ \\
\hline Constante & $\begin{array}{l}0.0833 * * * \\
(-0.0192)\end{array}$ & $\begin{array}{l}-1.859 * * * \\
(-0.021)\end{array}$ & \\
\hline
\end{tabular}

Número de observações: 235487. Observações censuradas: 51520 .

Desvios-padrão entre parêntesis: * significante a $10 \% ; * *$ significante a $5 \%$; *** significante a $1 \%$. 
No que tange a equação de rendimentos, há diferenças entre os resultados pelo segundo estagio de Heckman e por MQO em termos da significância estatística das covariadas e pelo resultado dos setores de atividade. Ser homem, branco e mais escolarizado contribui para rendimento do trabalho mais elevado. Ademais, o perfil côncavo do rendimento em relação ao ciclo de vida é captado pelo sinal positivo da variável idade e negativo do quadrado da idade. Em ambas as estimações, trabalhar no setor de serviços e construção civil garante salário hora mais alto do que na indústria em 2007. O sinal da variável educação profissional mostra que cursá-la melhora a inserção do trabalhador no mercado de trabalho ao garantir-lhe rendimento mais elevado em comparação aos que não a cursam.

\section{Considerações finais}

A educação profissional, como destacado várias vezes neste trabalho, é um tema de extrema relevância para o Brasil hoje. Capacitar a população de modo a facilitar seu ingresso no mercado de trabalho é importante para o progresso econômico e social do país. E aumentar a produtividade traz retornos que ultrapassam o indivíduo que se qualifica, tornando-se tão importante para o desenvolvimento econômico. Por se tratar de uma questão majoritariamente pública, como foi mostrado pela revisão histórica deste tipo de política no Brasil, identificar quem se beneficia da educação profissional auxilia na elaboração de políticas mais adequadas a este público.

A abrangência da educação profissional, no entanto, ainda é bastante restrita no Brasil, onde apenas $3,8 \%$ da população entre dez e 65 anos frequentava este tipo de ensino na época da pesquisa, sendo a qualificação profissional o curso mais procurado e de maior oferta, enquanto a graduação tecnológica se expande de maneira ainda restrita entre os brasileiros. Em relação ao perfil do indivíduo que busca este tipo de ensino, foi constatado que os que estão fora da PEA são os maiores frequentadores, o que aponta para a importância desta qualificação como meio de inserção no mercado de trabalho, aspecto ressaltado também pela faixa etária da maior parte dos estudantes, que são jovens de até 25 anos.

Em relação aos rendimentos, foi constatado o efeito positivo da educação profissional sobre os retornos do trabalho, o que corrobora o resultado encontrado anteriormente para o Brasil por Severnine e Orellano (2010), dentre outros. Retomando a discussão sobre capital humano, Becker (1993) e Mincer (2009) já apontavam, no início da formulação desta teoria, que a maior capacitação aumentaria a produtividade do trabalhador, e que tal aumento seria refletido num maior retorno salarial do trabalho.

A comprovação empírica desta teoria é relevante para impulsionar políticas que provêm educação profissional aos indivíduos, mostrando que, além de facilitar 
a entrada no mercado de trabalho, indivíduos qualificados tendem a ganhar mais que os não qualificados. Já no que diz respeito à especificidade do treinamento procurado pela maioria dos brasileiros, pode-se dizer que este é, em grande parte geral (não específico), pois os inativos são os que mais procuram educação profissional e, portanto, não estão buscando formação para uma firma empregadora específica, mas sim uma capacitação que possibilite ao indivíduo exercer funções em qualquer firma. Ademais, apreende-se uma questão de gênero na escolha das áreas de qualificação, o que, em termos de políticas públicas, deve ser evitado de modo a tornar a estrutura ocupacional menos segregacionista.

Ademais, no que tange à raça, iniciativas de inclusão social devem ser combinadas a políticas de transferência de renda, como é o caso do Bolsa Família, objetivando criar condições para que os pretos, contingente populacional mais vulnerável à situação de privação, encontrem oportunidades no mercado de trabalho.

Após traçar o perfil do trabalhador que cursa educação profissional e mostrar que o mercado de trabalho proporciona retornos maiores para os que frequentam estes cursos, esperamos que o planejamento de políticas públicas nessa área seja facilitado, adequando-as, como foi destacado nos objetivos deste estudo, às necessidades de quem realmente busca essa modalidade de curso como via para ingresso e reconhecimento no mercado de trabalho.

\section{Referências bibliográficas}

BECKER, Gary. Human Capital: a theoretical and empirical analysis, with special reference to education. Chicago: The University of Chicago Press, 1993.

BENZIL, Christian; HANSEN, Joergen; KRISTENSEN, Nicolai. Estimating complementarity between education and training. Institute dor the Study of Labor (IZA), 2008. (IZA Discussion Papers, 3882).

BHASKAR, V.; HOLDEN, Steinar. Wage differentiation via subsidized general training. Dec. 2002.

BORJAS, George. Labor economics. New York: McGraw-Hill, 1996.

BRASIL. Ministério da Educação. Fórum mundial de educação profissional e tecnológica. Disponível em: http://sitefmept.mec.gov.br/index.php?option $=$ com content $\&$ view $=$ article $\&$ id $=284 \% 3 \mathrm{Aedu}$ cacao-profissional-e-estrategica-para-insercao-do-brasil-no-mundo-afirma-

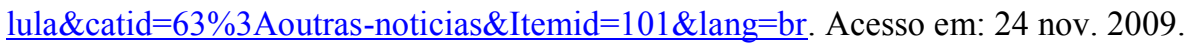

BULHÕES, Maria. Plano Nacional de Qualificação do Trabalhador - PLANFOR: acertos, limites e desafios vistos do extremo sul. São Paulo em Perspectiva, São Paulo, v. 18, n. 4, p. 39-49, 2004. 
CAHUC, Pierre; ZYLBERBERG, André. Labor economics. Massachusetts Institute of Technology Press, 2004.

CARD, D.; DINARDO, J. Skill biased technological change and rising wage inequality: some problems and puzzles. 2002. (NBER Working Paper, n. 8769).

CARNEIRO; CUNHA; HECKMAN. The technology of skill formation. Society for Economic Dynamics, 2004. (Meeting Papers, 681).

CLARK, Damon; FAHR, René. The promise of workplace training for non-college bound youth: theory and evidence from German apprenticeship. Centre for Economic Performance, London School of Economics, Feb. 2002. (Discussion Paper, n. 518).

FARIA, Lia et al. Uma reflexão sobre o trabalho e a educação profissional no Brasil. Revista Cientifica Digital da Faetec, v. 1, n. 1, 2008. Disponível em: http://www.faetec.rj.gov.br/desup/images/edutec/lia.pdf. Acesso em: 20 maio 2008.

FERREIRA, C. G. Processo de trabalho e relação salarial - um marco teórico-analítico para o estudo das formas capitalistas de produção industrial. Belo Horizonte: Cedeplar/UFMG, 1994. (Texto para Discussão, n. 37).

et al. Alternativas sueca, italiana e japonesa ao paradigma fordista: elementos para uma discussão sobre o caso brasileiro. Cadernos do CESIT, Campinas, Unicamp. IE, n. 4, 1991.

HADDAD, Fernando. O plano de desenvolvimento da educação: razões, princípios, programas. Brasília: Instituto Nacional de Estudos e Pesquisas Educacionais Anísio Teixeira, 2008.

HARVEY, David. A condição pós-moderna: uma pesquisa sobre as origens da mudança cultural. São Paulo: Loyola, 1993.

HECKMAN, James. Sample selection bias as a specification error. Econometrica, v. 47, n. 1, p. 153-162, jan. 1979.

. Inequality in America: what role for human capital policies? Focus, University of Wisconsin-Madison, Institute for Research on Poverty, v. 23, n. 5, p. 1-10, 2005.

HEIJKE, Hans; MENG, Christoph; RIS, Catherine. Fitting to the job: the role of generic and vocational competencies in adjustment and performance. Maastricht: ROA, Research Centre for Education and the Labour Market, 2003. (Research Memoranda, 001).

IBGE. Aspectos complementares da educação de jovens e adultos e educação profissional. Disponível em: http://www.ibge.gov.br/home/estatistica/populacao/trabalhoerendimento/ pnad2007/suplementos/jovens/publicacao_completa.pdf. Acesso em: 27 maio 2009a.

IBGE. Notas técnicas. Pesquisa Nacional por Amostra de Domicílios 2007. Disponível em: http://www.ibge.gov.br/home/estatistica/populacao/trabalhoerendimento/pnad2007/notas_si ntese.pdf. Acesso em: 29 de maio 2009b. 
KATZ, Laurence; AUTOR, David. Changes in the wage structure and earn-ings inequality. In: ASHENFELTER, Orley; LAYARD, P. R. G. (P. Richard G.). Handbook of labor economics. Amsterdam, 1998.

KUENZER, Acácia. A reforma do ensino técnico e suas conseqüências. In: EDUCAÇÃO profissional: tendências e desafios. Documento final do II Seminário sobre a Reforma do Ensino Profissional, Curitiba, Sindocefet-PR, 1999.

LEITE, Marcia. Reestruturação produtiva, novas tecnologias e novas formas de gestão da mão-de-obra. In: COMIN, Álavaro (Org.). O mundo do trabalho: crise e mudança no final do século. Campinas: Pagina Aberta: Scritta, 1994. p. 563-587.

LEUVEN, Edwin et al. Worker reciprocity and employer investment in training. Tinbergen Institute, 2002. (Discussion Paper, 2002/090-3).

MATTOSO, Jorge. O novo e inseguro mundo de trabalho nos países avançados. In: COMIN, Álavaro (Org.). O mundo do trabalho: crise e mudança no final do século. Campinas: Pagina Aberta: Scritta, 1994. p. 521-562.

MINCER, Jacob. Schooling, experience, and earnings. Disponível em: http://papers.nber.org/books/minc74-1. Acesso em: 29 abr. 2009.

PIRES, Julio. Ensino técnico e básico: a controvérsia dos anos 70 e as demandas contemporâneas do mercado de trabalho. In: KON, A. (Ed.). Estudos em economia industrial, trabalho e tecnologia. São Paulo: PUC-SP/Programa de Estudos Pós-Graduados em Economia Política / Núcleo de Pesquisas EITT-Economia Industrial, Trabalho e Tecnologia, 2001. p. 130-150.

SEVERNINI, Eduardo; ORELLANO, Verônica. O efeito do ensino profissionalizante sobre a probabilidade de inserção no mercado de trabalho e sobre a renda no período préPlanfor. Revista ANPEC, v. 11, p. 155-174, 2010.

WOOLDRIDGE, Jeffrey. Econometric analysis of cross section and panel data. Cambridge, Mass.: MIT Press, 2002.

Introdução à econometria: uma abordagem moderna. São Paulo: Pioneira

Thomson Learning, 2006. 